\title{
Social determinants of tuberculosis in Europe: a prospective ecological study
}

\author{
George B. Ploubidis*, Melissa J. Palmer*, Charlotte Blackmore*, Tek-Ang Lim*, \\ Davide Manissero", Andreas Sandgren ${ }^{\#}$ and Jan C. Semenza ${ }^{\#}$
}

ABSTRACT: Tuberculosis (TB) is considered to be a disease of poverty, since its incidence is exacerbated by socioeconomic factors, inconsistent or partial treatment practices, and immigration from endemic countries.

A prospective country level study, using a comprehensive dataset of TB incidence and prevalence taken from countries within the World Health Organization (WHO) European region, was conducted. We employed quintile regression to investigate the prospective association between baseline (measured in 2000) and a nation's wealth, level of egalitarianism, migration rate, health-related lifestyle and social capital with TB incidence and prevalence over a 10-yr period (2000-2009).

We found that $\sim 50 \%$ of TB variation is accounted for by a nation's wealth and level of egalitarianism. We observed a negative prospective association between logged gross domestic product and TB rates, and a positive prospective association between income inequality and TB.

National income levels per capita and income inequality are important predictors for TB incidence and prevalence in the WHO European region. They account for $50 \%$ of country-level variation, indicating the importance of a combined absolute and relative socioeconomic disadvantage in the development of TB. These findings also provide a tool for forecasting potential fluctuations in the level of TB epidemics in the WHO European region, with respect to socioeconomic changes.

KEYWORDS: Epidemiology, Europe, human ecology, social welfare, socioeconomic factors, tuberculosis

$\mathrm{n}$ Europe, where all countries are past the epidemiological transition [1], the majority of deaths $(86 \%)$ are attributed to chronic disease, with the shift in mortality rates from infectious disease to chronic disease occurring due to the successful control of communicable disease [2]. However, substantial inequalities or disparities in the health of different socioeconomic groups remain. Mortality and morbidity rates differ systematically by socioeconomic status throughout Europe; higher education, income, and social class are associated with a healthier lifestyle and a longer life expectancy [3-5]. With respect to communicable diseases, a systematic review on socioeconomic factors and infectious diseases in Europe highlighted the presence of differentials and attributed these to low levels of education, low occupational class, or low income level [6], as well as a high-risk health-related behaviour, which has also been linked to a low socioeconomic position [7].

Among communicable diseases, tuberculosis (TB) remains a global emergency. In 2009 TB was responsible for an estimated 1.9 million deaths worldwide with a further 9.4 million reported new cases of TB [8]. TB is considered to be a disease of the socially and economically disadvantaged, since its incidence is exacerbated by socioeconomic factors, inconsistent or partial treatment practices and immigration from countries in which the disease is endemic $[6,9,10]$. Reducing inequalities in TB incidence in Europe is, therefore, a goal that needs to be addressed, especially since the recent global financial crisis is expected to exacerbate health inequalities [11, 12]. However, the relatively small contribution of TB to overall mortality and morbidity makes the statistical analysis not feasible on the individual level and an ecological study is needed. Macrolevel variation and especially country-level differences provide us with an excellent opportunity to study the effect of social determinants on TB incidence and prevalence in Europe. In general, national differences in health indices may be valuable in providing insights into macro-level determinants of health, including structural and policy

\section{AFFILIATIONS}

${ }^{\star}$ Population Studies Dept, Faculty of Epidemiology and Population Health London School of Hygiene and Tropical Medicine, University of London, London, UK.

\#European Centre for Disease Prevention and Control (ECDC), Stockholm, Sweden.

CORRESPONDENCE

J.C. Semenza

European Centre for Disease Prevention and Control (ECDC) Tomtebodavagen $11 \mathrm{~A}$ Stockholm

Sweden

E-mail: Jan.Semenza@

ecdc.europa.eu

Received

Oct 212011

Accepted after revision: Dec 142011

First published online: Jan 202012 
TABLE 1 Descriptive statistics of all variables included in the models

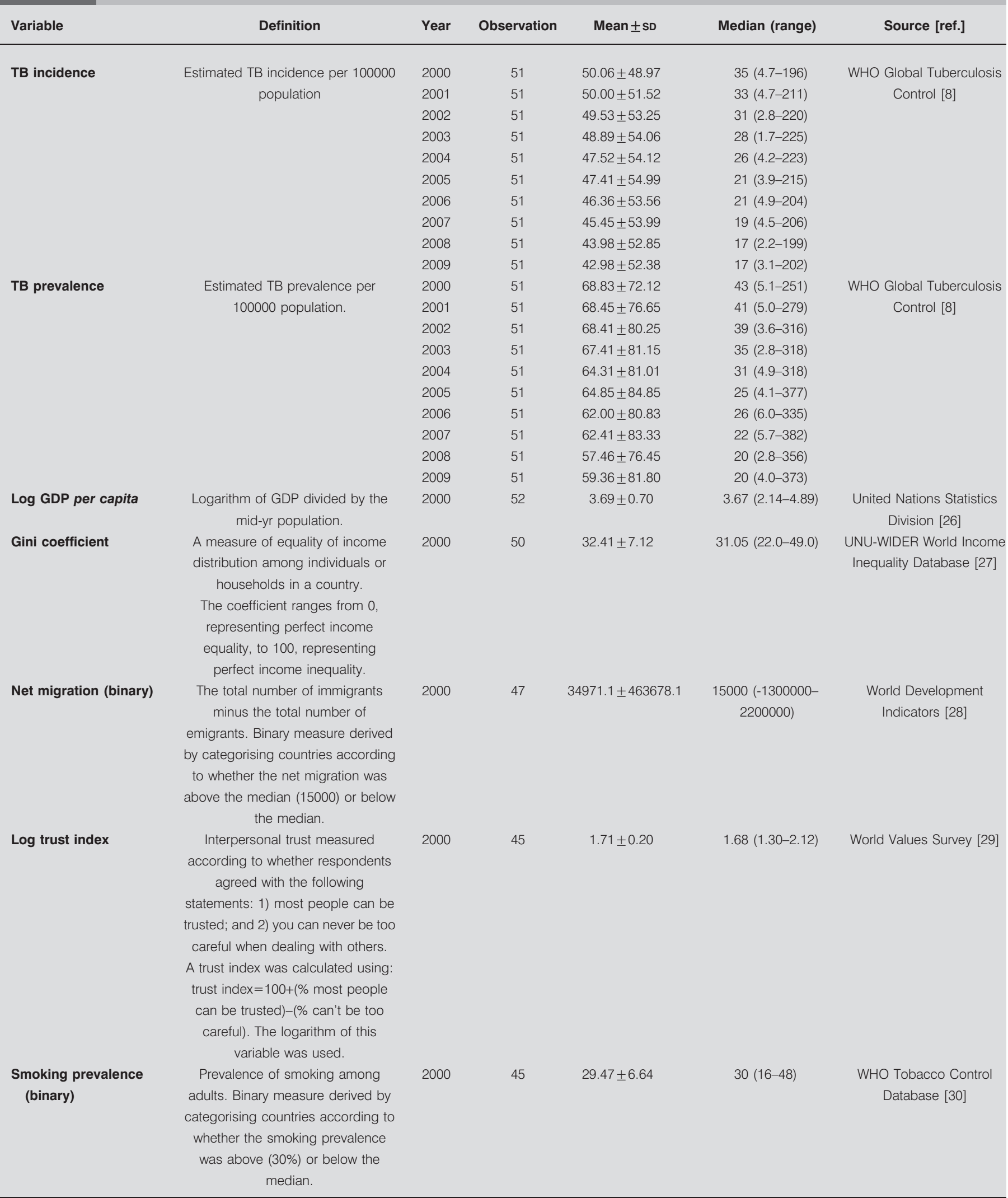

TB: tuberculosis; GDP: gross domestic product; WHO: World Health Organization; UNU-WIDER: United Nations University World Institute for Developments Economics Research. 
influences [13]. Further study might show which macro-level factors are most influential and maybe identify those that could be modified through intervention. Country-level health differences in Europe have been widely reported and the presence of country-level variation is consistent, despite the various health outcomes that have been used [4, 14-17], and Country-level health differences have also been reported with respect to TB prevalence [18]. Several explanations for the observed countrylevel variation have been suggested: a leading explanation concerns economic growth and development, which are viewed as important predictors of population health. In accordance with this hypothesis, gross domestic product (GDP) per capita has been consistently linked with population health [19], with wealthier countries in general having a better population health. Furthermore, income inequality, which is prevalent to varying degrees in all European countries, is thought to influence country-level variation, with several studies reporting an association between the Gini coefficient and population health [20]. Consistent with the lifestyle explanation of health inequalities, differences in health-related lifestyles have been found across Europe [21], and these are thought to be contributing to health differences between countries. Finally, from a psychosocial perspective, social capital and its dimensions, such as social trust and social participation, have been suggested as important predictors for country-level variation in health [22]. To this explanatory framework we added net migration rates for each country, since, to a certain extent, immigration in Europe originates from countries where TB is endemic [23, 24].

Motivated by finding that European countries present a highly heterogeneous situation in terms of TB epidemiology and control [25], our major aim in this macro-level ecological study is to investigate the concurrent and prospective effect of country-level social determinants on the prevalence and incidence of TB in 55 countries of the World Health Organization European region, using a comprehensive country-level dataset spanning $10 \mathrm{yrs}$ (2000-2009).

\section{METHODS}

\section{Data sources and measures}

In table 1 we present the descriptive statistics and sources of information for all variables in the model. With respect to the predictors at baseline (2000), we employed an indicator of the

TABLE 2 Quintile regression parameters

\begin{tabular}{|c|c|c|c|c|c|c|}
\hline Year & Log GDP per capita & Gini coefficient & Net migration & Log trust index & Smoking prevalence & Pseudo $\mathbf{R}^{2}$ \\
\hline \multicolumn{7}{|l|}{2000} \\
\hline Incidence & $-46.22,(-68.29--24.15)^{\star \star}$ & $1.75(0.06-3.43)^{*}$ & $15.35(-8.94-39.64)$ & $4.81(-39.41-49.03)$ & $-5.97(-22.47-10.53)$ & 0.534 \\
\hline Prevalence & $-56.61(-95.20--18.01)^{\star \star}$ & $1.43(-0.85-4.95)$ & $11.78(-26.63-50.19)$ & $5.67(-66.03-77.37)$ & $-6.46(-30.65-17.74)$ & 0.49 \\
\hline \multicolumn{7}{|l|}{2001} \\
\hline Incidence & $-40.44(-62.21--18.66)^{\star *}$ & $1.78(0.31-3.26)^{\star}$ & $9.21(-15.31-33.74)$ & $0.23(-44.17-44.63)$ & $-6.45(-21.38-8.48)$ & 0.549 \\
\hline Prevalence & $-57.89(94.59--21.19)$ & $2.11(-0.24,4.47)$ & $11.06(-25.23-47.35)$ & $18.33(-45.25-81.91)$ & $-6.53(-30.72-17.66)$ & 0.508 \\
\hline \multicolumn{7}{|l|}{2002} \\
\hline Incidence & $-40.25(-62.93--17.58)$ & $1.96(0.49-3.42)^{\star}$ & $12.55(-10.04-35.14)$ & $-1.43(-41.21-38.34)$ & $-7.55(-20.64-5.53)$ & 0.555 \\
\hline Prevalence & $-57.86(-96.26--19.45)^{\star *}$ & $2.18(-0.25-4.62)$ & $11.14(-22.75-45.03)$ & $22.52(-32.52-77.56)$ & $-7.82(-28.16-12.52)$ & 0.514 \\
\hline \multicolumn{7}{|l|}{2003} \\
\hline Incidence & $-41.60(-64.59--18.61)^{\star \star}$ & $2.21(0.77-3.65)^{\star \star}$ & $16.99(-5.31-39.29)$ & $2.84(-41.55-47.24)$ & $-6.74(-21.53-8.05)$ & 0.536 \\
\hline Prevalence & $-54.37(-89.95--18.79)^{\star *}$ & $2.23(0.15-4.32)^{\star}$ & $10.43(-21.04-41.90)$ & $21.18(-34.53-76.90)$ & $-7.01(-27.55-13.54)$ & 0.492 \\
\hline \multicolumn{7}{|l|}{2004} \\
\hline Incidence & $-39.51(-61.50--17.52)^{\star *}$ & $2.33(0.82-3.84)^{\star \star}$ & $15.65(-5.74-37.04)$ & $6.01(-36.43-48.46)$ & $-4.60(-19.10-9.90)$ & 0.546 \\
\hline Prevalence & $-52.74(-86.14--19.34)^{\star *}$ & $2.74(0.74-4.75)^{\star \star}$ & $17.87(-9.71-45.46)$ & $21.50(-33.51-76.52)$ & $-5.31(-24.56-13.94)$ & 0.512 \\
\hline \multicolumn{7}{|l|}{2005} \\
\hline Incidence & $-39.87(-63.09--16.65)^{\star *}$ & $2.36(1.03-3.69)^{\star *}$ & $13.87(-7.72-35.46)$ & $7.22(-30.57-45.00)$ & $-2.91(-17.09-11.27)$ & 0.533 \\
\hline Prevalence & $-49.21(-87.93--10.50)^{\star \star}$ & $2.67(0.77-4.57)^{\star \star}$ & $13.61(-16.80-44.03)$ & $15.08(-36.98-67.14)$ & $-3.54(-21.81-14.73)$ & 0.48 \\
\hline \multicolumn{7}{|l|}{2006} \\
\hline Incidence & $-41.20(-66.01--16.38)^{\star \star}$ & $2.31(0.84-3.78)^{\star \star}$ & $13.83(-6.95-34.62)$ & $10.48(-26.40-47.36)$ & $-3.05(-17.07-10.97)$ & 0.531 \\
\hline Prevalence & $-46.76(-86.09--7.43)^{\star}$ & $2.66(0.50-4.83)^{*}$ & $14.51(-17.74-46.77)$ & $9.71(-44.50-63.91)$ & $-2.35(-22.73-18.03)$ & 0.474 \\
\hline \multicolumn{7}{|l|}{2007} \\
\hline Incidence & $-40.74(-68.29--13.19)^{\star}$ & $2.12(0.68-3.53)^{\star}$ & $14.41(-7.38-36.19)$ & $10.71(-27.98-49.40)$ & $-3.63(-17.36-10.11)$ & 0.517 \\
\hline Prevalence & $-54.85(-94.68--15.02)^{\star *}$ & $2.33(0.19-4.48)^{\star}$ & $20.57(-8.58-49.72)$ & $19.78(-35.21-74.77)$ & $-3.46(-23.72-16.79)$ & 0.447 \\
\hline \multicolumn{7}{|l|}{2008} \\
\hline Incidence & $-43.83(-71.44--16.22)^{\star}$ & $2.14(0.68-3.60)^{\star}$ & $13.82(-7.02-34.66)$ & $18.48(-22.62-59.58)$ & $-5.85(-19.61-7.92)$ & 0.516 \\
\hline Prevalence & $-48.00(-76.33--19.66)^{\star \star}$ & $2.51(0.75-4.26)^{\star \star}$ & $12.15(-9.81-34.11)$ & $20.36(-25.81-66.52)$ & $-2.41(-16.68-11.86)$ & 0.484 \\
\hline \multicolumn{7}{|l|}{2009} \\
\hline Incidence & $-43.35(-69.54--17.17)^{*}$ & $2.32(0.77-3.87)^{\star}$ & $15.65(-5.06-36.35)$ & $18.19(-19.90-56.28)$ & $-4.77(-18.54-9.00)$ & 0.491 \\
\hline Prevalence & $-52.64(-91.29--14.00)$ & $2.14(0.16-4.12)^{\star}$ & $18.01(-11.78-47.80)$ & $23.79(-26.46-74.04)$ & $-4.67(-23.05-13.70)$ & 0.443 \\
\hline
\end{tabular}

Data are presented as quintile regression parameters (95\% confidence interval). GDP: gross domestic product. *: $p<0.05 ;{ }^{\star}$ : $p<0.01$. 
prevalence of smoking as a proxy measure of health-related lifestyle, since there is a well-known association between smoking and TB outcome [31]. The Gini coefficient was employed as a measure of income inequality; it is the most commonly used measure of inequality and varies between 0 , which reflects complete equality and 1 , which indicates complete inequality $[20,32,33]$. Logged GDP per capita was used as a measure for the standard of living, whereas a social trust index was used as an indicator of social capital. In our models we included countries with complete information on all predictors as well as the two outcomes $(n=42)$.

\section{Statistical modelling}

Once the appropriate indicators were derived we employed appropriate quintile regression models to obtain the adjusted for other country-level predictor effect of education, wealth distribution and other indicators of social inequalities on TB rates. In ecological studies, where country-level aggregated data is used, the distributional assumptions of linear regression rarely hold. Therefore, quintile regression offers an attractive alternative that relaxes such assumptions since no parametric distributional form is assumed for the error distribution and, therefore, can be used with skewed distributions since the median of the dependent variable instead of the mean is modelled. All models were estimated with STATA statistical software package (version 11.1; STATA Corporation, College Station, TX, USA).

\section{RESULTS}

There is considerable country-level variation with respect to TB incidence (1.7-225 per 100,000) and prevalence (2.8-382 per $100,000)$ in Europe (table 1). In table 2 we present quintile regression parameter estimates, their respective confidence intervals, $\mathrm{p}$-values derived from bootstrapped standard errors (10,000 replications) and pseudo $R^{2}$ for each model. Our models accounted for $\sim 50 \%$ of the variation in both outcomes either at baseline or prospectively (pseudo $\mathrm{R}^{2}$ for each $\mathrm{yr}$ presented in table 2). Logged GDP per capita measured at baseline (2000) was negatively associated with the prevalence and incidence of $\mathrm{TB}$, indicating both cross- sectional and prospectively that countries with higher GDP per capita have lower TB incidence and prevalence (table 2 and fig. 1). On the contrary, income inequality as approximated by the Gini coefficient measured at baseline was negatively associated with TB incidence, both concurrently and also prospectively. We observed a lagged effect of income inequality on TB prevalence, since the Gini coefficient measured at baseline had a prospective negative association with TB prevalence ( 3 yrs after baseline). This was an expected finding since the influence of inequality on incidence from the baseline onwards would eventually be expressed on the association between income inequality and TB prevalence (table 2 and fig 2). We did not observe any significant association between the remaining three predictors, net migration, social trust, and smoking with either incidence or prevalence of TB.

\section{DISCUSSION}

There is a large heterogeneity in TB prevalence and incidence in the WHO Europe region, a finding in accordance with previous studies [25]. We found that $\sim 50 \%$ of this variation is due to a nation's wealth and level of economic development, but it is also driven by the income distribution within nations, indicating that both absolute and relative socioeconomic disadvantage

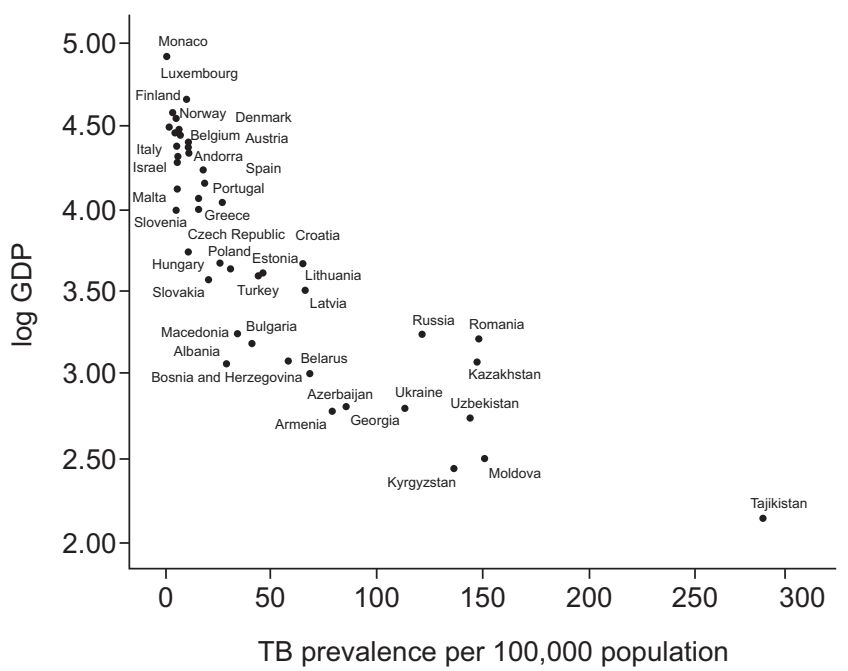

FIGURE 1. Scatter plot of the association between the baseline (2000) logged gross domestic product (GDP) and tuberculosis (TB) prevalence in 2005.

are influential in the development of TB. We observed a strong negative association between GDP and both TB outcomes, a finding in accordance with previous research on TB $[18,34]$ and other health outcomes [15], but not in line with previous studies where a non-linear association between GDP and health was suggested, with diminishing marginal effects of economic development once a certain standard of living had been achieved [35]. It appears that as a country grows wealthier it has more resources to spend on health-promoting social programmes, such as public sanitation, potable water, and health awareness initiatives. Furthermore, individuals are able to purchase healthier food, improved housing, live in safer environments and have better access to healthcare [36, 37] compared with their counterparts in poorer countries, as a result aggregated TB rates and other population health statistics are improved.

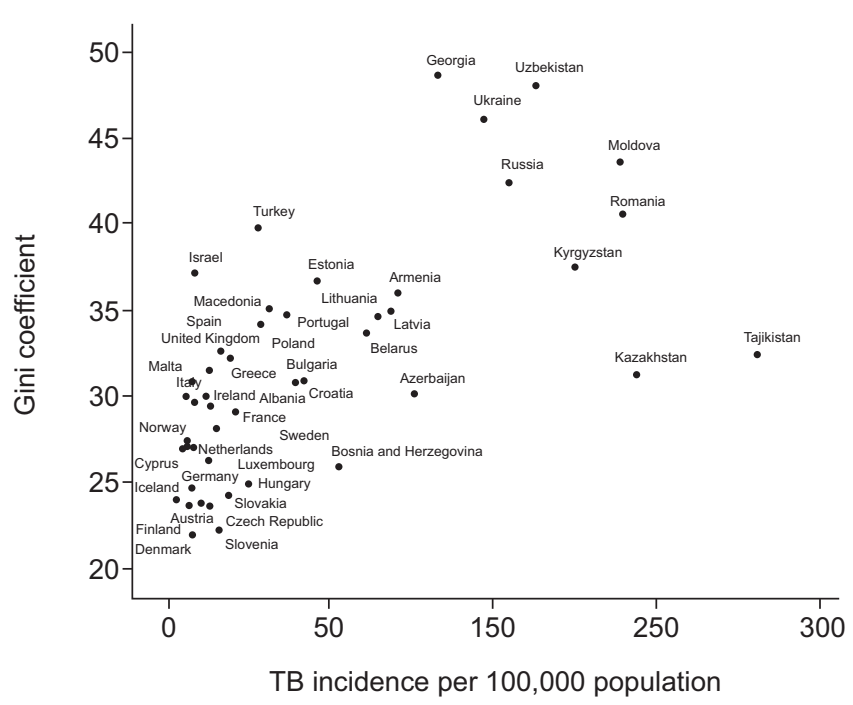

FIGURE 2. Scatter plot of the association between baseline Gini coefficient 2000 and tuberculosis (TB) incidence in 2004 
Income inequality was a significant predictor of country-level variation in TB rates, with less inequality being associated with lower incidence and prevalence. The finding that country-level variation in health is largely associated with differences in the level of egalitarianism of each country, as measured by the Gini coefficient, is in accordance with some previous findings $[20,38]$, but not with others [38-41]. However, these studies had a global, rather than European, focus [35]. It appears that in the European countries considered here, more unequal distribution of income leads to a larger proportion of individuals with incomes less than the minimum required for healthy living $[42,43]$, or below the poverty line. Thus, despite the overall wealth and level of economic development within a nation, income inequality increases the numbers of individuals within a country that have low vaccine coverage, engage in high-risk health behaviour, and have limited access to healthcare. These are all factors which are relevant for or correlate with the incidence and prevalence of TB. Another potential explanation of the effect of income inequality on TB is that income inequality results in increased urban poverty, which is associated with well-known risk factors for TB, such as overcrowding and polluted environments [44].

We did not observe an association between migration and smoking with either TB incidence or prevalence, despite the fact that both predictors are thought to be associated with TB outcomes [23, 45]. We speculate that any potential effect of the two predictors is being picked up by income inequality; since immigrants from countries where TB is endemic are more likely to be disadvantaged with respect to income and the same can be argued for smokers. To further elucidate this issue we conducted sensitivity analysis replacing net migration in our models with available information on the proportion of TB cases that were foreign born (2007 and 2009). Similarly with net migration, the proportion of foreign born TB cases was not associated with overall TB incidence or prevalence. Income inequality remained a strong predictor of both TB incidence and prevalence, supporting our speculation that the effect of net migration on TB is being picked up by income inequality. On the contrary, the effect of GDP became nonsignificant, a finding due to the tendency of affluent countries to receive a relatively high number of migrants from countries where TB is endemic [46]; this idea is supported by the high correlations $(r>0.8)$ between GDP and the proportion of foreign born TB cases (unpublished data).

We did not observe an association between social trust and country-level variation in $\mathrm{TB}$, a finding in agreement with some previous studies [15, 47]. Although it has been suggested elsewhere that income inequality leads to more violence, less social cohesion and lower levels of social trust [20], it appears that the mechanism, through which income inequality influences TB outcomes, is not related to social trust. Considering that differences in social capital that have been reported in Europe [48, 49], an explanation for the lack of association between social trust and $\mathrm{TB}$ may be that social capital dimensions do not have, perhaps as yet, any theoretical links to $\mathrm{TB}$ and other infectious diseases, but are mostly relevant to chronic diseases, which have known links to negative psychosocial processes according to the social stress hypothesis [50].

The major limitation of this study is the reliance on ecological, country-level data, which is subject to well-known ecological fallacy. In other words, we cannot be certain that the aggregate effects we have found apply to the population at the individual level. Furthermore, our statistical analysis was carried out using countries with complete data. We estimated several multiple, imputation models for sensitivity purposes in order to increase the analytic sample (unpublished data). The results of these models were similar with the one we present here, suggesting that the exclusion of missing data in our statistical analysis did not bias our results.

\section{Conclusion}

This study is based on the comprehensive prospective dataset of country-level predictors of TB rates and the use of appropriate models to quantify their association. However, despite the strong predictive associations between logged GDP, the Gini coefficient and the two TB outcomes, our models accounted for $\sim 50 \%$ of the country-level variation in TB rates and it is plausible that unmeasured confounders may have biased our estimates. Further research is needed to identify these country-level predictors that account for the remaining variance, for example it has been proposed that characteristics of the welfare states, such as social benefits and generally high social expenditure, are related to improved population health [51] and this may be relevant to TB rates in the European and neighbouring countries, considered here. Finally, regardless of these uncertainties, the findings suggest that measures of wealth, inequality and the magnitude in their variation at regional and national level could be used to forecast changes in TB epidemics when facing socioeconomic changes at the European and global level.

\section{STATEMENT OF INTEREST}

None declared.

\section{REFERENCES}

1 Omran AR. The epidemiologic transition: a theory of the epidemiology of population change. Milbank Mem Fund Q 1971; 49: 509-538.

2 World Health Organization. Gaining Health. The European Strategy for the Prevention and Control of Noncommunicable Diseases. Copenhagen, World Health Organization, 2006. www.euro.who.int/ en/what-we-publish/abstracts/gaining-health.-the-european-strategyfor-the-prevention-and-control-of-noncommunicable-diseases

3 Mackenbach JP, Kunst AE, Cavelaars A, et al. Socioeconomic inequalities in morbidity and mortality in western Europe. Lancet 1997; 349: 1655-1659.

4 Mackenbach JP, Stirbu I, Roskam AJR, et al. Socioeconomic inequalities in health in 22 European countries. $N$ Engl J of Med 2008; 358: 2468-2481.

5 Marmot MG, Smith GD, Stansfeld S, et al. Health inequalities among British civil servants: the Whitehall II study. Lancet 1991; 337: 1387-1393.

6 Semenza JC, Giesecke J. Intervening to reduce inequalities in infections in Europe. Am J Public Health 2008; 98: 787-792.

$7 \mathrm{Kasl} \mathrm{SV}$, Berkman L. Health consequences of the experience of migration. Annu Rev Public Health 1983; 4: 69-90.

8 World Health Organization. Global Tuberculosis Control: WHO Report 2010. WHO/HTM/TB/2010.7. Geneva, World Health Organization, 2010.

9 Drobniewski F, PablosMendez A, Raviglione MC. Epidemiology of tuberculosis in the world. Semin Respir Crit Care Med 1997; 18: 419-429. 
10 Raviglione MC, Snider DE, Kochi A. Global epidemiology of tuberculosis. Morbidity and mortality of a worldwide epidemic. JAMA 1995; 273: 220-226.

11 Rechel B, Suhrcke M, Tsolova S, et al. Economic crisis and communicable disease control in Europe: a scoping study among national experts. Health Policy 2011; 103: 168-175.

12 Suhrcke M, Stuckler D, Suk JE, et al. The impact of economic crises on communicable disease transmission and control: a systematic review of the evidence. PLoS One 2011; 6: e20724.

13 McKee M. An agenda for public health research in Europe. Eur J Public Health 1998; 8: 3-7.

14 Eikemo TA, Bambra $\mathrm{C}$, Judge $\mathrm{K}$, et al. Welfare state regimes and differences in self-perceived health in Europe: A multilevel analysis. Soc Sci Med 2008; 66: 2281-2295.

15 Olsen KM, Dahl S-Å. Health differences between European countries. Soc Sci Med 2007; 64: 1665-1678.

16 Karlsson $\mathrm{M}$, Nilsson $\mathrm{T}$, Lyttkens $\mathrm{CH}$, et al. Income inequality and health: Importance of a cross-country perspective. Soc Sci Med 2010; 70: 875-885.

17 Ploubidis GB, Grundy E. Later-life mental health in Europe: a countrylevel comparison. J Gerontol B Psychol Sci Soc Sci 2009; 64: 666-676.

18 Suk JE, Manissero D, Buscher G, et al. Wealth inequality and tuberculosis elimination in Eürope. Emerg Infect Dis 2009; 15: 1812-1814.

19 Beckfield J. Does income inequality harm health? New crossnational evidence. J Health Socl Behav 2004; 45: 231-248.

20 Wilkinson RG, Pickett KE. Income inequality and population health: a review and explanation of the evidence. Soc Sci Med 2006; 62: $1768-1784$.

21 de Groot L, Verheijden MW, de Henauw S, et al. Lifestyle, nutritional status, health, and mortality in elderly people across Europe: a review of the longitudinal results of the SENECA study. J Gerontol A Biol Sci Med Sci 2004; 59: 1277-1284.

22 Carlson P. Self-perceived health in East and West Europe: another European health divide. Socl Sci Med 1998; 46: 1355-1366.

23 Moore DAJ, Lightstone L, Javid B, et al. High rates of tuberculosis in end-stage renal failure: the impact of international migration. Emerg Infect Dis 2002; 8: 77-78.

24 Rieder HL, Zellweger JP, Raviglione MC, et al. Tuberculosiscontrol in Europe and international migration. Eur Respir J 1994; 7 : 1545-1553.

25 Manissero D, Hollo V, Huitric E, et al. Analysis of tuberculosis treatment outcomes in the European Union and European Economic Area: efforts needed towards optimal case management and control. Euro Surveill 2010; 15: pii 19514.

26 United Nations Statistics Division. http://unstats.un.org/unsd/ default.htm Date last updated: December 7, 2011. Date last accessed: January 8, 2012.

27 United Nations University. World Income Inequality Database V2.0c May 2008. www.wider.unu.edu/research/Database/en_GB/ database/ Date last accessed: December 7, 2011.

28 The World Bank. World Development Indicators. http://data. worldbank.org/data-catalog/world-development-indicators Date last accessed: December, 7: 2011.

29 World Value Survey. www.worldvaluessurvey.org/ Date last accessed: December 7, 2011.

30 World Health Organization. Tuberculosis (TB). www.who.int/tb/ country/data/download/en/index.html Date last accessed: December 7, 2011.
31 Gajalakshmi V, Peto R, Kanaka TS, et al. Smoking and mortality from tuberculosis and other diseases in India: retrospective study of 43000 adult male deaths and 35000 controls. Lancet 2003; 362: 507-515.

32 Weymark JA. Generalized Gini inequality indeces. Math Soc Sci 1981; 1: 409-430.

33 Gastwirt JL. Estimation of Lorenz curve and Gini index. Rev Econ Stat 1972; 54: 306-316.

34 Biggs B, King L, Basu S, et al. Is wealthier always healthier? The impact of national income level, inequality, and poverty on public health in Latin America. Socl Sci Med 2010; 71: 266-273.

35 Rodgers GB. Income and inequality as determinants of mortality: an international cross-section analysis. Popul Stud 1979; 33: 343-351.

36 Kaplan GA, Pamuk ER, Lynch JW, et al. Inequality in income and mortality in the United States: analysis of mortality and potential pathways. BMJ 1996; 312: 999-1003.

37 Lynch JW, Smith GD, Kaplan GA, et al. Income inequality and mortality: importance to health of individual income, psychosocial environment, or material conditions. BMJ 2000; 320: 1200-1204.

38 Wilkinson RG. Socioeconomic determinants of health. Health inequalities: relative or absolute material standards? BMJ 1997; 314: 591-595.

39 Jen $\mathrm{MH}$, Jones $\mathrm{K}$, Johnston R. Global variations in health: evaluating Wilkinson's income inequality hypothesis using the World Values Survey. Soc Sci Med 2009; 68: 643-653.

40 Jen $\mathrm{MH}$, Jones $\mathrm{K}$, Johnston R. Compositional and contextual approaches to the study of health behaviour and outcomes: using multi-level modelling to evaluate Wilkinson's income inequality hypothesis. Health Place 2009; 15: 198-203.

41 Lynch J, Smith GD, Harper S, et al. Is income inequality a determinant of population health? Part 1. A systematic review. Milbank Q 2004; 82: 5-99.

42 Morris JN, Donkin AJM, Wonderling D, et al. A minimum income for healthy living. J Epidemiol Community Health 2000; 54: 885-889.

43 Morris JN, Wilkinson P, Dangour AD, et al. Defining a minimum income for healthy living (MIHL): older age, England. Int $J$ Epidemiol 2007; 36: 1300-1307.

44 Godfrey R, Julien M. Urbanisation and health. Clin Med 2005; 5: 137-141.

45 Kolappan C, Gopi PG. Tobacco smoking and pulmonary tuberculosis. Thorax 2002; 57: 964-966.

46 Klinkenberg E, Manissero D, Semenza JC, et al. Migrant tuberculosis screening in the EU/EEA: yield, coverage and limitations. Eur Respir J 2009; 34: 1180-1189.

47 Lynch J, Smith GD, Hillemeier M, et al. Income inequality, the psychosocial environment, and health: comparisons of wealthy nations. Lancet 2001; 358: 194-200.

48 Beugelsdijk S, Van Schaik T. Differences in social capital between 54 Western European regions. Reg Stud 2005; 39: 1053-1064.

49 Kaariainen J, Lehtonen $H$. The variety of social capital in welfare state regimes: a comparative study of 21 countries. Eur Soc 2006; 8: 27-57.

50 Pearlin LI. The sociological study of stress. J Health Soc Behav 1989; 30: 241-56.

51 Navarro V, Shi L. The political context of social inequalities and health. Soc Sci Med 2001; 52: 481-491. 